\title{
Ferritina sérica en el segundo trimestre para predicción de parto de pretérmino
}

\author{
Martha Rondon-Tapia ${ }^{1}$, Eduardo Reyna-Villasmil ${ }^{1 *}$, Jorly Mejia-Montilla ${ }^{1}$, Nadia Reyna-Villasmil ${ }^{1}$, \\ Duly Torres-Cepeda ${ }^{1}$, Joel Santos-Bolívar ${ }^{1}$, Andreina Fernández-Ramírez ${ }^{1,2}$.
}

Resumen: Introducción: el parto pretérmino es una de las principales causas de morbimortalidad perinatal. La ferritina se asocia con varias reacciones de fase aguda, incluyendo condiciones inflamatorias. Se ha propuesto que las mediciones de las concentraciones de ferritina sérica como un marcador inflamatorio que puede predecir en forma efectiva este evento en embarazadas de bajo riesgo. Objetivo: establecer la utilidad de las concentraciones séricas de ferritina en el segundo trimestre para la predicción del parto pretérmino. Métodos: las muestras de ferritina sérica se tomaron entre las 24 y 28 semanas de embarazo. Todos los embarazos fueron seguidos hasta el parto. Se evaluaron las características generales, concentraciones séricas de ferritina y eficacia pronostica. Resultados: la edad gestacional al momento de la determinación de las concentraciones séricas de ferritina fue de 26,2 +/- 1,1 semanas para el grupo A y $25,9+/-1,1$ semanas para el grupo B $(p=n s)$. La edad gestacional promedio al momento del parto en el grupo A fue de 32,9+/- 1,2 semanas y para el grupo $B$ fue de $38,9+-1,5$ semanas $(p<0,0001)$. No se encontraron diferencias estadísticamente significativas en la edad materna, índice de masa corporal y antecedentes de parto pretérmino ( $\mathrm{p}=\mathrm{ns})$. Las pacientes del grupo A (92,2 +/- 16,3 ng/ $\mathrm{mL}$ ) presentaron concentraciones séricas significativamente más altas de ferritina comparadas con las embarazadas del grupo $B$ (59,3 $+/-14,1 \mathrm{ng} / \mathrm{mL} \mathrm{pg} / \mathrm{mL} ; \mathrm{p}<0,0001)$. Un valor de corte de $80 \mathrm{ng} / \mathrm{mL}$ presentó un valor por debajo de la curva de 0,95 con sensibilidad $73,0 \%$, especificidad $93,0 \%$, valor predictivo positivo $49,3 \%$ y valor predictivo negativo $97,3 \%$. Conclusión: las concentraciones séricas de ferritina son útiles en la predicción del parto pretérmino.

Palabras clave: ferritina; parto pretérmino; predicción.

Abstract: Introduction: Preterm delivery is one of main causes of perinatal morbi-mortality. Ferritin is associated to various acute phase reactions, including inflammatory conditions. It has been proposed that measurement of serum ferritin concentrations as an inflammatory marker that could predict effectively this event in low-risk pregnant women. Objective: To establish usefulness of serum ferritin concentrations in second trimester for the prediction of preterm delivery. Methods: Serum ferritin samples were taken between 24 and 28 weeks of pregnancy. All patients were followed until delivery. General characteristics, serum ferritin concentrations and prognostic efficacy were evaluated Results: The mean gestation age at measurement of serum concentrations of ferritin was $26.2+/-1.1$ weeks in group $A$ and $25.9+/-1.1$ weeks in group B $(p=n s)$. Mean gestational age at delivery for group A was $32.9+/-1.2$ weeks and for group $B$ was $38.9+/-1.5$ weeks $(p<0.0001)$. There were not found significant differences in maternal age, body mass index and history of preterm labor $(p=n s)$. Group A patients $(92.2+/-16.3 \mathrm{ng} / \mathrm{mL})$ presented higher serum ferritin concentrations than group B $(59.3+/-$ $14.1 \mathrm{ng} / \mathrm{mL} ; \mathrm{p}<0.0001$ ). A cut-off value of $80 \mathrm{ng} / \mathrm{mL}$ had a value under curve of 0.95 with a sensitivity of $73.0 \%$, specificity of $93.0 \%$, positive predictive value of $49.3 \%$ and negative predictive value of $97.3 \%$. Conclusion: Serum ferritinconcentrations are useful for the prediction of preterm delivery.

Keywords: Ferritin; Preterm delivery; Prediction.

Fecha de envío: 06 de Junio de 2016 - Fecha de aceptación: 30 de Agosto de 2016

\section{Introducción}

El parto pretérmino es definido como contracciones uterinas regulares antes de las 37 semanas completas de embarazo con membranas intactas y 4 centímetros o más de dilatación cervical. Es una de las principales causas de morbimortalidad perinatal, ya que representa cerca del $70 \%$ de las muertes neonatales por

1) Servicio de Obstetricia y Ginecología - Maternidad "Dr. Nerio Belloso" Hospital Central "Dr. Urquinaona". Maracaibo, Estado Zulia. Venezuela 2) Universidad del Zulia. Maracaibo. Venezuela.

Autor de Correspondencia: sippenbauch@gmail.com 
problemas relacionados con el desarrollo incompleto de sus órganos - sistemas y $50 \%$ de las secuelas neurológicas a largo plazo (Herbst \& Nilsson, 2006).

La patogénesis del parto pretérmino aún no está bien comprendida, pero podría representar la activación idiopática temprana del proceso normal de trabajo de parto o secundaria a algún factor patológico. Se conocen varios procesos patológicos que producen activación del eje hipotálamo - hipófisis - suprarrenal, inflamación decidual - corioamniótica - sistémica, hemorragia decidual y distensión patológica del útero precipitan el parto pretérmino (Yeast \& Lu, 2007).

Evidencia experimental y clínica ha relacionado la asociación entre procesos inflamatorios intrauterinos y el parto pretérmino. En efecto, las embarazadas con parto pretérmino tienen concentraciones más elevadas de algunos indicadores inflamatorios amnióticos y séricos comparados con aquellas mujeres que tienen partos a término (Saade et al., 2016; Yoneda et al., 2016). Se han estudiado varios marcadores biológicos y bioquímicos que permiten la identificación temprana de las pacientes con riesgo de parto pretérmino.

La ferritina es producida en el hígado, bazo, hueso y placenta al igual que es liberada por leucocitos que reaccionan contra las infecciones (Ramsey et al., 2002; Tyrda et al., 2015). Es una proteína intracelular almacenadora de hierro identificada como marcador diagnóstico y sus altas concentraciones séricas se asocian con varias reacciones de fase aguda, incluyendo condiciones inflamatorias (Soubasi et al., 2010). Algunos investigadores han reportado una relación entre las concentraciones elevadas de ferritina sérica y el parto pretérmino (Weintraub et al., 2005; Lee et al., 2006; Alwan et al., 2015). En relación con el papel fundamental de la inflamación sobre la aparición y progresión del parto pretérmino, se ha propuesto que las mediciones de las concentraciones de ferritina sérica como un marcador inflamatorio que puede predecir en forma efectiva este evento en embarazadas de bajo riesgo. Sin embargo, el poder predictivo y el mejor valor de corte para este marcador en la predicción del parto pretérmino aún no ha sido substancialmente evaluado.

El objetivo de la investigación fue establecer la utilidad de las concentraciones séricas de ferritina en el segundo trimestre para la predicción del parto pretérmino.

\section{Métodos}

Se realizó un estudio prospectivo entre enero de 2012 y octubre de 2015 que incluyó 613 pacientes con embarazos simples que fueron referidas al Hospital Central "Dr. Urquinaona”. Se obtuvo aprobación del Comité de Ética del Hospital antes del inicio de la investigación y se obtuvo el consentimiento por escrito en todas las pacientes.
Las pacientes con condiciones que producen alteraciones de las concentraciones de ferritina como infecciones crónicas, alteraciones inflamatorias, neoplasias conocidas, antecedentes de uso de corticosteroides, procesos hematológicos agudos o crónicos, enfermedad hepática al momento de la investigación, vaginitis, infección del tracto urinario, insuficiencia renal, hipertensión crónica o el uso de cualquier sustancia que pueda interferir con las concentraciones o producción de ferritina fueron excluidas. También se excluyeron pacientes con condiciones obstétricas como embarazos múltiples, restricción del crecimiento intrauterino del feto, anomalías placentarias, placenta previa, alteraciones de la frecuencia cardiaca fetal, sangrado genital durante el embarazo, anomalías cromosómicas o congénitas, presencia de infecciones intrauterinas (por ejemplo, corioamnionitis), rotura prematura de membranas, polihidramnios, incompetencia ístmico-cervical o malformaciones uterinas conocidas, placenta previa, diabetes mellitus y preeclampsia/eclampsia. Las pacientes con antecedentes de hábito tabáquico o con embarazos con edad gestacional incierta no fueron seleccionadas para la investigación.

Una vez seleccionadas las pacientes para el estudio, se llenó una ficha de recolección de datos que incluyó: identificación de la paciente, antecedentes personales y gineco-obstétricos, control prenatal, edad de gestación (por fecha de última regla o ecografía del primer trimestre). La edad gestacional se calculó sobre la fecha de la última menstruación, antes de la semana 20 del embarazo. Todas las muestras de sangre se tomaron entre las 24 y 28 semanas de embarazo para determinar las concentraciones de ferritina. Todos los embarazos fueron seguidos hasta el parto, las pacientes con partos pretérminos antes de las 37 semanas (grupo A) y aquellas con parto a término luego de las 37 semanas (grupo B) y se compararon con respecto a la edad materna, edad gestacional al momento del parto y concentraciones de ferritina.

Las muestras de sangre venosa $(10 \mathrm{~mL})$ se tomaron en un tubo de ensayo seco y estéril para la evaluación bioquímica, al momento del ingreso al hospital, sin importar el momento del día y antes de la administración de cualquier medicamento. El plasma y el suero fueron protegidos de la luz ultravioleta y separados en los $30 \mathrm{~min}$ siguientes a la toma de la muestra. Posteriormente fue centrifugado a $4.000 \mathrm{rpm}$ por $10 \mathrm{~min}$, separado en alícuotas y almacenado a $-70^{\circ} \mathrm{C}$ hasta el momento del análisis. La determinación del valor del hematocrito materno se realizó con un autoanalizador. Las determinaciones de las concentraciones de ferritina se realizaron con un kit comercial de inmunoanálisis enzimático de quimioluminiscencia (Immulite 2000, Diagnostic Products) con coeficientes de variación intra e inter ensayo de 8,7 y 7\%. El límite inferior de detección de la prueba es de $0,1 \mathrm{mg} / \mathrm{dl}$. 
Los valores obtenidos se presentaron como promedio +/- desviación estándar. Se utilizó la prueba t de Student para comparar las variables continuas. La precisión de las concentraciones séricas de ferritina para la predicción de parto pretérmino se presenta en función de sensibilidad, especificidad, valor predictivo positivo y valor predictivo negativo. Se utilizó el análisis operador-receptor para determinar el mejor valor de corte para la predicción. Se consideró $\mathrm{p}<0,05$ como estadísticamente significativa.

\section{Resultados}

Se seleccionaron un total de 800 pacientes para la investigación de las cuales 191 fueron excluidas por presentar diferentes complicaciones obstétricas por las cuales fueron excluidas de la investigación. Otras 48 pacientes se retiraron o se perdieron del seguimiento y no se pudo establecer el tipo de parto que presentaron. Un total de 613 embarazadas se encontraban disponibles para la evaluación final, de las cuales en el grupo, 52 embarazadas (8,4\%) presentaron parto pretérmino (grupo A; casos) y 561 embarazadas $(91,8 \%$ ) que presentaron partos a término (grupo $B$, controles). Las características de ambos grupos se muestran en la tabla 1. La edad materna fue de 30,3 +/- 6,9 años y 29,8 +/- 7,4 años para los grupos A y B, respectivamente $(p=0,270)$. No se encontraron diferencias significativas en la edad gestacional al momento del examen, índice de masa corporal y antecedentes de parto pretérmino $(p=n s)$. No se encontraron diferencias significativas en la frecuencia de primigestas entre ambos grupos $(p=n s)$. La edad gestacional al momento del examen fue a las 26,2 +/- 1,1 (mediana 26,1) semanas en el grupo $A$ y a las 25,9+/-1,1 (mediana 25,8) semanas en el grupo $B(p=n s$ ). La edad gestacional promedio al momento del parto en el grupo $A$ fue de 32,9+/- 1,2 semanas (mediana 33 semanas) y para el grupo $B$ fue de $38,9+-1,5$ semanas (mediana 39 semanas) $(p<0,0001)$.

Tabla 1: Características generales.

\begin{tabular}{|c|c|c|c|}
\hline $\begin{array}{l}\text { Promedio +/- desviación } \\
\text { estándar }\end{array}$ & $\begin{array}{c}\text { GRUPO A } \\
\text { Casos } \\
(n=52)\end{array}$ & $\begin{array}{l}\text { GRUPO B } \\
\text { Controles } \\
(n=561)\end{array}$ & $p$ \\
\hline Edad materna, años & $30,3+1-6,9$ & $29,8+/-7,4$ & ns \\
\hline $\begin{array}{l}\text { Edad gestacional al momento } \\
\text { del examen, semanas }\end{array}$ & $26,2+/-1,1$ & $25,9+/-1,1$ & ns \\
\hline Índice de masa corporal, $\mathrm{Kg} / \mathrm{m}^{2}$ & $26,7+/-3,7$ & $26,3+/-4$ & ns \\
\hline Primigesta, n (\%) & $30(57,6)$ & $314(55,9)$ & ns \\
\hline $\begin{array}{l}\text { Antecedente de parto } \\
\text { pretérmino, } \mathrm{n}(\%)\end{array}$ & $11(21,1)$ & $111(19,8)$ & ns \\
\hline
\end{tabular}

En la figura 1 se muestran las concentraciones séricas de ferritina en cada uno de los grupos. Las pacientes del grupo A presentaron concentraciones significativamente más altas $(92,2+/-16,3 \mathrm{ng} / \mathrm{mL})$ comparadas con las embarazadas del grupo $B(59,3+/-14,1 \mathrm{ng} / \mathrm{mL} ; \mathrm{p}<0,0001)$.

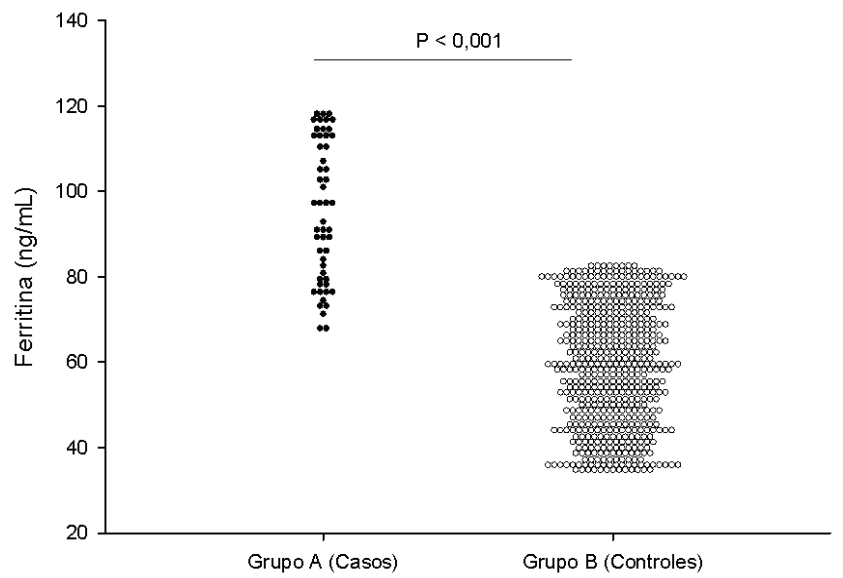

Figura 1. Concentraciones séricas de ferritina en cada uno de los grupos de estudio.

En la figura 2 se muestra la curva operador receptor para la precisión diagnóstica de la ferritina sérica para la predicción de parto pretérmino. Un valor de corte de $80 \mathrm{ng} / \mathrm{mL}$ presentó un valor por debajo de la curva de 0,95 (intervalo de confianza [IC] del 95\%; 0,92 - 0,97) con una sensibilidad del 73,0\% (IC del 95\%; 58,9 - 84,4), especificidad del 93,0\% (IC del 95\%; 90,6 - 95,0\%), valor predictivo positivo del 49,3\% (IC del 95\%; 37,7 - 61,0\%) y valor predictivo negativo del 97,3\% (IC del 95\%; 95,6 - 98,5\%). La relación de probabilidad positiva fue de 10,512 (IC del 95\%; 7,761 - 14,250), la relación de probabilidad negativa fue de 0,167 (IC del 95\%; 0,087 - 0,299) y la exactitud diagnóstica fue de $91,3 \%$.

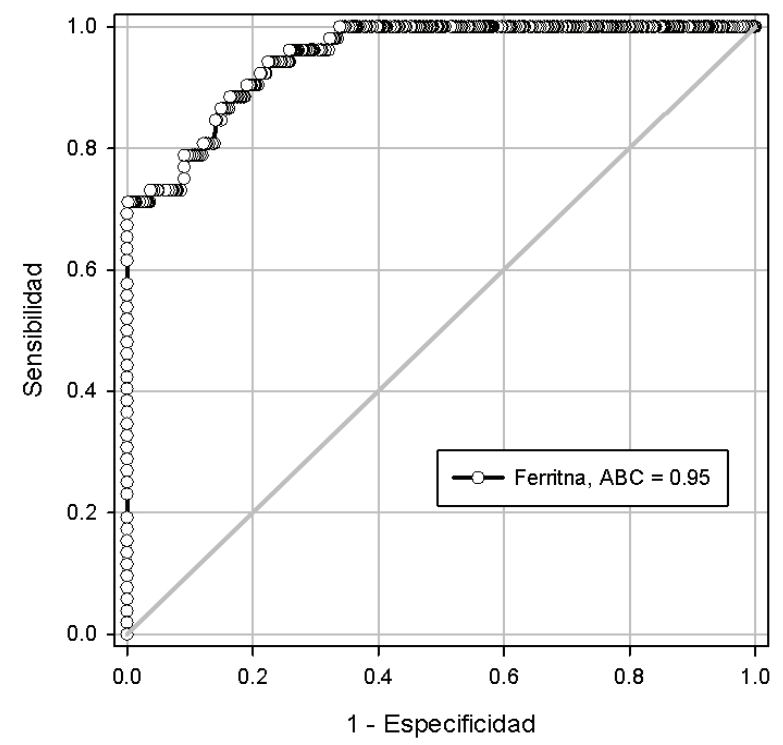

Figura 2. Curva operador-receptor para las concentraciones séricas de ferritina en la predicción del parto pretérmino. 


\section{Discusión}

El parto pretérmino y la prematuridad relacionada son factores predisponentes que aumentan la morbimortalidad perinatal. Diferentes factores séricos, amnióticos y cérvico-vaginales han sido el centro de atención de diferentes investigaciones y algunos estudios han demostrado que el incremento de las concentraciones de los factores inflamatorios en las embarazadas puede estar asociado a parto pretérmino (Wei et al., 2010; Davey et al., 2015). Los resultados de esta investigación demuestran que las elevaciones de las concentraciones séricas de ferritina durante el segundo trimestre predicen el riesgo de parto pretérmino, particularmente cuando su valor excede $80 \mathrm{ng} / \mathrm{mL}$. Debido a que la ferritina es un reactante de fase aguda, las concentraciones elevadas en estas circunstancias no reflejan el estado de los depósitos de hierro, sino que puede ser utilizado como un bio-marcador de infección / inflamación aguda o crónica (Wang et al., 2010).

La ferritina, una proteína de almacenamiento de hierro, juega un papel importante en la defensa del huésped contra infecciones bacterianas mediante el secuestro del hierro, el cual se considera un elemento fundamental para el crecimiento bacteriano. Se ha demostrado que la isoferritina placentaria, una isoforma placentaria de la ferritina, está presente en el sinciciotrofoblasto, células de Hofbauer y macrófagos de la decidua (Maymon et al., 2002; Ramsey et al., 2002). Se ha sugerido que la ferritina producida por los macrófagos infiltra la interfase corio-decidual posterior a la colonización bacteriana. El embarazo predispone a infecciones cérvico-vaginales debido a la alteración del $\mathrm{pH}$ vaginal. Las concentraciones séricas elevadas de ferritina podrían indicar la exposición a un agente infeccioso o presencia de alguna condición inflamatoria no infecciosa junto a un nivel adecuado de concentraciones de hierro (Weintraub et al., 2005). Se ha sugerido una posible asociación entre las concentraciones séricas elevadas de ferritina y las alteraciones del crecimiento fetal, por lo que este indicador puede servir como marcador de la respuesta inflamatoria vascular no infecciosa (Cappelletti et al., 2016).

Diferentes autores han demostrado resultados similares a los hallazgos de la presente investigación y algunos de ellos han establecido el posible papel de esta en la predicción del parto pretérmino (Weintraub et al., 2005; Singh et al., 2011; Beta et al., 2012; Movahedi et al., 2012). La mayoría de esos estudios han indicado una asociación entre la ferritina sérica y el parto pretérmino. Ulmer et al. (1988) observaron correlación entre las concentraciones de ferritina sérica y parto pretérmino o rotura prematura de membranas. También observaron asociación entre la incidencia de parto pretérmino y bajas concentraciones de ferritina en el segundo trimestre. Un estudio posterior demostró que la elevación de las concentraciones de ferritina sérica durante el segundo trimestre eran predictivas de parto pretérmino, lo cual puede estar relacionado con deficiencias de hierro y folato en el embarazo temprano o antecedentes de infección reciente (Tamura et al., 1996).

Signh et al., (2011) seleccionaron 40 pacientes con parto pretérmino y 40 mujeres con partos a término y compararon varios parámetros incluyendo hormona adenocorticotropa (ACTH), prolactina, hormona tiroestimulante (TSH), ferritina y fosfatasa alcalina (ALP). Las concentraciones de ACTH, ferritina y ALP fueron significativamente más altas en las pacientes que presentaron partos pretérminos comparado con los controles. La ferritina fue considerada el mejor marcador con un área bajo la curva igual a 0,96 comparado con 0,88 del ACTH. Otros estudio también evaluó la curva operador respuesta para el valor diagnóstico de la ferritina sérica (Movahedi et al., 2012). Seleccionaron 222 pacientes con embarazos simples, de las cuales 69 presentaron parto pretérmino y determinaron las concentraciones de ferritina a las $24-26$ semanas. $Y$ concluyeron que las concentraciones de ferritina fueron más elevadas en aquellas que presentaron parto pretérmino. Un valor de $22,5 \mathrm{ng} / \mathrm{mL}$ presentó la mejor combinación de sensibilidad (78,3\%), especificidad $(83,0 \%)$, valor predictivo positivo $(67,5 \%)$ y valor predictivo negativo $(89,4 \%)$ para la predicción de parto pretérmino.

Todos estos hallazgos parecen indicar que las concentraciones de ferritina en el segundo trimestre pueden ser predictoras de parto pretérmino espontáneo, especialmente en aquellos que ocurren en las edades gestacionales más tempranas. Toda esta evidencia sugiere la presencia de algunos posibles mecanismos. La presencia de altas concentraciones de ferritina puede reflejar una reacción de fase aguda a infecciones o inflamaciones subclínica del tracto genital (Ramsey et al., 2002). Además, esto puede explicar el proceso por el cual las infecciones asociadas al parto pretérmino puede causar daño tisular producto del aumento de las concentraciones de ferritina que actúa como un reactante de fase aguda (Tamura et al., 1996; Goel et al., 2003).

Se han sugerido varios valores de corte para las concentraciones séricas de ferritina para la predicción de parto pretérmino. Goel et al. (2003) propusieron que una concentración sérica de ferritina superior a $40 \mathrm{ng} / \mathrm{mL}$ como valor de corte para la predicción de parto pretérmino. Para esta investigación el mejor punto de corte para la predicción de parto pretérmino, se seleccionó el valor de $80 \mathrm{ng} / \mathrm{mL}$, ya que suministró buenos valores de sensibilidad y especificidad. En esta investigación se seleccionó un valor bastante más alto que lo reportado en investigaciones previas, logrando aumentar la capacidad de discriminación de la prueba. 


\section{Conclusión}

Sobre la base de los resultados de la investigación, se concluye que las concentraciones séricas de ferritina en el segundo trimestre son útiles en la predicción de parto pretérmino.

\section{Declaración de aspectos éticos}

Reconocimiento de autoría: Todos los autores declaran que han realizado aportes a la idea, diseño del estudio, recolección de datos, análisis e interpretación de datos, revisión crítica del contenido intelectual y aprobación final del manuscrito que estamos enviando. Responsabilidades éticas: Protección de personas. Los autores declaran que los procedimientos seguidos se conformaron a las normas éticas del comité de experimentación humana responsable y de acuerdo con la Asociación Médica Mundial y la Declaración de Helsinki. Confidencialidad de los datos: Los autores declaran que han seguido los protocolos del Hospital Central "Dr. Urquinaona" sobre la publicación de datos de pacientes. Derecho a la privacidad y consentimiento informado: Los autores han obtenido el consentimiento informado de los pacientes y/o sujetos referidos en el artículo. Este documento obra en poder del autor de correspondencia. Financiamiento: Los autores certifican que no han recibido apoyos financieros, equipos, en personal de trabajo o en especie de personas, instituciones públicas y/o privadas para la realización del estudio. Conflicto de intereses: Los autores declaran no tener ningún conflicto de intereses.

\section{Referencias}

Alwan NA, Cade JE, McArdle HJ, Greenwood DC, Hayes HE \& Simpson NA. (2015). Maternal iron status in early pregnancy and birth outcomes: insights from the Baby's Vascular health and Iron in Pregnancy study. British Journal of Nutrition 113, 1985-1992.

Beta J, Poon LC, Bakalis S, Mosimann B \& Nicolaides KH. (2012). Maternal serum ferritin at 11- to 13-week gestation in spontaneous early preterm delivery. The Journal of Maternal-Fetal \& Neonatal Medicine 25, 1852-1855.

Cappelletti M, Della Bella S, Ferrazzi E, Mavilio D \& Divanovic S. (2016). Inflammation and preterm birth. Journal of Leukocyte Biology 99, 67-78.

Davey MA, Watson L, Rayner JA \& Rowlands S. (2015). Risk-scoring systems for predicting preterm birth with the aim of reducing associated adverse outcomes. Cochrane Database of Systematic Reviews 10, CD004902.
Goel A, Jain V, Gupta I \& Varma N. (2003). Serial serum ferritin estimation in pregnant women at risk of preterm labor. Acta Obstetricia et Gynecologica Scandinavica 82, 129-132.

Herbst A \& Nilsson C. (2006). Diagnosis of early preterm labour. British Journal of Obstetrics and Gynaecology 113, 60-67.

Lee HS, Kim MS, Kim MH, Kim YJ \& Kim WY. (2006). Iron status and its association with pregnancy outcome in Korean pregnant women. European Journal of Clinical Nutrition 60, 1130-1135.

Maymon R, Jauniaux E \& Moroz C. (2002). Enhanced expression of the immunoregulator, p43-placental isoferritin, in Down's syndrome placentae and fetal kidneys. Molecular Human Reproduction 8 1125-1128.

Movahedi M, Saiedi M, Gharipour M \& Aghadavoudi O. (2012). Diagnostic performance and discriminative value of the serum ferritin level for predicting preterm labor. Journal of Research in Medical Sciences 17, 164-166.

Ramsey PS, Tamura T, Goldenberg RL, Mercer BM, lams JD, Meis PJ, Moawad AH, Das A, Van Dorsten JP, Caritis SN, Thurnau G, Dombrowski MP, Miodovnik M \& National Institute of Child Health and Human Development, Maternal-Fetal Medicine Units Network. (2002). The preterm prediction study: elevated cervical ferritin levels at 22 to 24 weeks of gestation are associated with spontaneous preterm delivery in asymptomatic women. American Journal of Obstetrics \& Gynecology 186, 458-463.

Saade GR, Boggess KA, Sullivan SA, Markenson GR, lams JD, Coonrod DV, Pereira LM, Esplin MS, Cousins LM, Lam GK, Hoffman MK, Severinsen RD, Pugmire T, Flick JS, Fox AC, Lueth AJ, Rust SR, Mazzola E, Hsu C, Dufford MT, Bradford CL, Ichetovkin IE, Fleischer TC, Polpitiya AD, Critchfield GC, Kearney PE, Boniface JJ \& Hickok DE. (2016). Development and validation of a spontaneous preterm delivery predictor in asymptomatic women. American Journal of Obstetrics \& Gynecology 214, 633.e1-633.e24.

Singh B, Goswami B, Gupta N, Bajaj AD \& Mallika V. (2011). Potential biochemical markers for preterm labor: a pilot study in north India. Indian Journal of Clinical Biochemistry 26, 41-45.

Soubasi V, Petridou S, Sarafidis K, Tsantali Ch, Diamanti E, Buonocore G \& Drossou-Agakidou V. (2010). Association of increased maternal ferritin levels with gestational diabetes and intra-uterine growth retardation. Diabetes \& Metabolism 36, 58-63. 
Rondón et al.

Tamura T, Goldenberg RL, Johnston KE, Cliver SP \& Hickey CA. (1996). Serum ferritin: a predictor of early spontaneous preterm delivery. Obstetrics \& Gynecology 87, 360-365.

Tvrda E, Peer R, Sikka SC \& Agarwal A. (2015). Iron and copper in male reproduction: a double-edged sword. Journal of Assisted Reproduction and Genetics 32, 3-16.

Ulmer HU \&, Goepel E (1988). Anemia, ferritin and preterm labor. Journal of Perinatal Medicine 16, 459-465.

Wang W, Knovich MA, Coffman LG, Torti FM \& Torti SV. (2010). Serum ferritin: Past, present and future. Biochimica et Biophysica Acta 1800, 760-769.

Wei SQ, Fraser W \& Luo ZC. (2010). Inflammatory cytokines and spontaneous preterm birth in asymptomatic women: a systematic review. Obstetrics \& Gynecology 116, 393-401.
Weintraub AY, Sheiner E, Mazor M, Levy A, Tevet A, Paamoni O \& Wiznitzer A. (2005). Maternal serum ferritin concentration in patients with preterm labor and intact membranes. The Journal of Maternal-Fetal \& Neonatal Medicine 18, 163-166.

Yeast JD \& Lu G. (2007). Biochemical markers for the prediction of preterm delivery. Clinics in Perinatology 34, 573-586.

Yoneda S, Shiozaki A, Yoneda N, Ito M, Shima T, Fukuda K, Ueno T, Niimi H, Kitajima I, Kigawa M \& Saito S. (2016). Antibiotic Therapy Increases the Risk of Preterm Birth in Preterm Labor without Intra-Amniotic Microbes, but may Prolong the Gestation Period in Preterm Labor with Microbes, Evaluated by Rapid and High-Sensitive PCR System. American Journal of Reproductive Immunology 75, 440-450. 